\title{
Comparison of 4D flow and 2D PC MRI blood flow quantification in children and young adults with congenital heart disease
}

\author{
Maya Gabbour ${ }^{1 *}$, Cynthia Rigsby ${ }^{1,2}$, Michael Markl ${ }^{2,3}$, Susanne Schnell ${ }^{2}$, Kelly B Jarvis ${ }^{2}$, Roger A de Freitas ${ }^{4,5}$, \\ Andrada R Popescu ${ }^{1,2}$, Joshua D Robinson ${ }^{4,5}$ \\ From 16th Annual SCMR Scientific Sessions \\ San Francisco, CA, USA. 31 January - 3 February 2013
}

\section{Background}

Echocardiography (echo) is the primary imaging modality for assessment of aortic and pulmonary blood flow velocities. 2D phase contrast (PC) MRI provides better access to all segments of the aortic and pulmonary system and is considered the standard for evaluating blood flow. Both techniques are limited by velocity analysis in $2 \mathrm{D}$ planes and by single-direction velocity measurement which may be inadequate to characterize the complex 3D hemodynamics in congenital heart disease (CHD). 4D flow MRI provides simultaneous assessment of 3D blood flow characteristics of all vessels within a 3D volume and offers the ability to retrospectively quantify blood flow parameters at selectable regions of interest. The aim of this study is to test the potential of 4D flow for accuracy of quantification of aortic and pulmonary flow parameters compared to the reference standards echo and 2D PC MRI in children and young adults with CHD.

\section{Methods}

32 patients with CHD who underwent simultaneous 4D flow and 2D PC MRI and echo within 9 months of MRI were retrospectively included. 2D PC MRI flow quantification in the aortic root (Ao), pulmonary trunk (PT), and right and left pulmonary arteries (RPA, LPA) was analyzed using Medis (Medis, Leiden, The Netherlands). 4D flow data analysis included calculation of a 3D-PC-angiogram which was used to position analysis planes in the Ao, PT, LPA and RPA (EnSight, CEI, Apex, NC) for quantification of net flow, regurgitant fraction, Qp:Qs, and peak velocities. Ao peak velocities were assessed by echo. Linear

'Department of Medical Imaging, Ann \& Robert H Lurie Children's Hospital of Chicago, Chicago, IL, USA

Full list of author information is available at the end of the article regression analysis was performed. Pearson's correlation coefficient $(r)$ was calculated. A correlation with $\mathrm{p}<0.05$ was considered significant.

\section{Results}

Patient characteristics are listed in Table 1. Mean time between MRI and echo was 2.7 months. Excellent agreement was found between 4D flow and 2D PC MRI for quantification of net flow $(\mathrm{r}=0.95, \mathrm{p}<0.001)$ and regurgitant fraction $(\mathrm{r}=0.91, \mathrm{p}<0.001)$ in the Ao, PT, RPA and LPA (Figure 1). For peak velocities, a significant but more moderate relationship $(r=0.46, p<0.001$, Figure 1$)$ between 4D flow and 2D PC MRI was found. After excluding patients with shunts $(n=2)$, Fontan circulation $(n=3)$, and with incomplete 2D PC MRI data $(\mathrm{n}=6)$, Qp:Qs showed good agreement between $4 \mathrm{D}$ flow and 2D PC MRI $(\mathrm{r}=0.63, \mathrm{p}=0.001)$. Noticeably, Qp:Qs based on 4D flow MRI showed a better approximation of the expected ratio of 1 ( 0.98 for 4D flow vs. 0.93 for 2D PC MRI). For aortic peak velocities, both 2D PC and 4D flow MRI demonstrated good and similar agreement with echo $(r=0.58$, $\mathrm{p}<0.003$ and $\mathrm{r}=0.55, \mathrm{p}=0.005$, respectively)

\section{Conclusions}

Flow quantification based on 4D flow MRI showed goodexcellent correlation for clinically relevant flow parameters for the characterization of CHD such as pulmonary and aortic peak velocities, net flow, regurgitant fraction and Qp:Qs compared to the references standards 2D PC MRI and echo.

\section{Funding}

Grant support NIH R01HL115828 and NUCATS Dixon Award. 
Table 1 Patient population characteristics

\begin{tabular}{|c|c|c|}
\hline PT\# & Age (yrs) & Diagnosis \\
\hline 1 & 14 & TOF, post repair \\
\hline 2 & 6 & TOF, post repair \\
\hline 3 & 20 & TOF, post repair \\
\hline 4 & 10 & TOF, post repair \\
\hline 5 & 7 & TOF, post repair \\
\hline 6 & 6 & TOF, post repair \\
\hline 7 & 11 & TOF/absent pulmonary valve, post repair \\
\hline 8 & 14 & TOF, AVSD, post repair with RV to PA conduit, RPA stent \\
\hline 9 & 10 & TOF/pulmonary atresia, post Rastelli and right unifocalization \\
\hline 10 & 11 & TOF/pulmonary artresia, post repair with RV to PA conduit \\
\hline 11 & 5 & TOF/pulmonary atresia, post bilateral unifocalization and RV to PA conduit \\
\hline 12 & 5 & d-TGA post arterial switch \\
\hline 13 & 16 & d-TGA post arterial switch \\
\hline 14 & 6 & d-TGA post arterial switch \\
\hline 15 & 7 & d-TGA post arterial switch \\
\hline 16 & 29 & CC-TGA \\
\hline 17 & 28 & BAV, post Ross \\
\hline 18 & 10 & BAV, post Ross \\
\hline 19 & 16 & Aortic coarctation, post subclavian flap repair \\
\hline 20 & 7 & Severe unrepaired aortic coarctation \\
\hline 21 & 11 & Ventricular ectopy \\
\hline 22 & 14 & ASD, VSD post repair with pulmonary valve stenosis \\
\hline 23 & 12 & VSD and pulmonary stenosis post repair, vascular ring \\
\hline 24 & 5 & LV non-compaction \\
\hline 25 & 10 & Truncus ateriosus, post repair with RV-PA conduit \\
\hline 26 & 20 & d-TGA, tricuspid atresia, pulmonary stenosis, s/p lateral tunnel Fontan \\
\hline 27 & 21 & DORV, mitral atresia, post fenestrated lateral Fontan \\
\hline 28 & 9 & Pulmonary atresia, post Fantan \\
\hline 29 & 19 & Williams syndrome and subaortic stenosis, post resection of subaortic fibrous ring \\
\hline 30 & 26 & Castleman's syndrome and subaortic stenosis, post resection of subaortic fibrous ring \\
\hline 31 & 12 & Mild hyoplasia of the distal transverse aortic arch \\
\hline 32 & 16 & Heart murmur \\
\hline
\end{tabular}

Abbreviation key: TOF, tetralogy of Fallot; AVSC, atrioventrincular septal defect; RV, right ventricle; PA, pulmonary artery; RPA, right pulmonary artery; d-TGA, dtransposition of the great arteries; Cc-TGA, congenitally corrected transposition of the great arteries; BAV, bicommisural aortic valve; ASD, atrial septal defect; VSD, ventricular septal defect; LV, left ventricle; DORV, double outlet right ventricle.

\section{Author details}

'Department of Medical Imaging, Ann \& Robert H Lurie Children's Hospital of Chicago, Chicago, IL, USA. ${ }^{2}$ Department of Radiology, Northwestern University Feinberg School of Medicine, Chicago, IL, USA. ${ }^{3}$ Department of Biomedical Engineering, Northwestern University, Chicago, IL, USA. ${ }^{4}$ Division of Pediatric Cardiology, Ann \& Robert H Lurie Children's Hospital of Chicago, Chicago, IL, USA. ${ }^{5}$ Department of Pediatrics, Northwestern University Feinberg School of Medicine, Chicago, IL, USA.

Published: 30 January 2013

doi:10.1186/1532-429X-15-S1-E90

Cite this article as: Gabbour et al:: Comparison of 4D flow and 2D PC MRI blood flow quantification in children and young adults with congenital heart disease. Journal of Cardiovascular Magnetic Resonance 2013 15(Suppl 1):E90.

\section{Submit your next manuscript to BioMed Central and take full advantage of:}

- Convenient online submission

- Thorough peer review

- No space constraints or color figure charges

- Immediate publication on acceptance

- Inclusion in PubMed, CAS, Scopus and Google Scholar

- Research which is freely available for redistribution

Submit your manuscript at www.biomedcentral.com/submit
() Biomed Central 